\title{
Contesting Internet governance: global dissent and disparities in the management of cyberspace resources
}

\author{
D. Drissel \\ Iowa Central Community College, USA
}

\begin{abstract}
This article explores Internet governance in depth, focusing on the emerging global controversy surrounding the multijurisdictional regulation of the Net's core technical infrastructure. Cyberspace regulatory inequities existing between the Global North and Global South are highlighted, with allegations of American unilateralism discussed in particular. Divergent ideological and sociopolitical approaches to Internet governance are examined, with the current US-centric model of corporate self-regulation compared to an emergent multilateral intergovernmental regulatory paradigm. The relative lack of Southern influence and power over Internet political/administrative structures is investigated in this regard. The growing controversy surrounding the US-government sponsored Internet Corporation for Assigned Names and Numbers (ICANN) is addressed. Highlights of debates from international forums dedicated to discussing Internet governance-related topics are presented, including possible structural reforms and sources of resistance to multilateral initiatives. Various stances of stakeholders involved in the debate over ICANN and other Internet governance actors are evaluated, with a special emphasis on the views of developing nations such as China, India, and Brazil. Proposals for reforming Internet governance and enhancing international trust in regulatory processes are proposed.

Keywords: Internet governance, global digital divide, regulation and selfregulation, multilateralism and unilateralism, Global South, ethos of the Internet, Internet Corporation for Assigned Names and Numbers (ICANN), domain name system, World Summit on the Information Society.
\end{abstract}




\section{Introduction}

The Internet has in recent years become a major focal point of global political contention, fueled by national, regional, and hemispheric disparities in the allocation of technological and informational resources. While the Information Revolution has dramatically altered everyday life in the Global North, the Southern hemisphere remains populated with a relatively large number of technological have-nots. Lagging far behind the developed world in the penetration and diffusion of affordable and reliable information communication technologies (ICTs), many Southern nations have grown increasingly frustrated with the global digital divide. But such concerns are not simply about insufficient access to computers, phone lines, and other equipment and technical skills. Rather, there is an emerging global debate over who (or what) should manage the Internet's core technical infrastructure and whether or not major changes to the US-dominated "self-regulatory" system of Internet oversight are needed.

Until recently, such contentious questions were either downplayed or ignored in discussions concerning North-South technological inequities. But increasingly, such issues are being debated in intergovernmental forums focusing on the root causes of the global digital divide. Consequently, the concept of "Internet governance" has emerged as the latest techno-political catchphrase, broadly defined to include not only the power of states in regulating online transactions, but also the mosaic of nongovernmental and intergovernmental bodies involved in coordinating the norms, policies, protocols, operational procedures, and technical infrastructure of cyberspace.

The Internet Corporation for Assigned Names and Numbers (ICANN), a nonprofit corporation operating under the purview of the US Department of Commerce, is by far the most powerful Internet governance body in the world today. As manager of the Domain Name System (DNS), ICANN oversees the most important ("top level") generic categories of online addresses such as .com, .org, and .net. Ostensibly nongovernmental, ICANN is often accused of favouring American political and corporate interests over European and especially Global South concerns. For this reason, disputes have arisen amongst governments and other stakeholders concerning allegations of American regulatory unilateralism. Significantly, various alternative models of Internet governance have been proposed and discussed at recent UN-sponsored symposiums such as the World Summit on the Information Society (WSIS).

This article will investigate the subject of Internet governance, focusing primarily on international disparities of cyberspace regulatory controls and infrastructural inequities that exist between the developed and developing worlds. Conflicting ideological and sociopolitical approaches for Internet governance will be examined, with the current US-centric model of corporate self-regulation compared to an emergent multilateral intergovernmental regulatory paradigm. In this regard, the libertarian/neo-liberal inclination for a privatised, mostly Americanised, form of Internet governance is contrasted with 
a more cosmopolitan, multilateral stance that proposes global organisational oversight of cyberspace technical resources and infrastructure.

\section{Conceptualising Internet governance}

Internet governance is a relatively new concept, devised in response to the relatively rapid proliferation of e-commerce and other online transactions worldwide. Initially, there was a great deal of resistance to even using the phrase, much less devoting entire international conferences to discussions about the phenomenon. Due in large measure to popular perceptions of the Internet as a kind of regulatory-free zone, the concept of Internet governance had little traction until recent years. But with the growing incidence of such Internetrelated problems as online fraud and identity theft, privacy incursions, copyright infringements, trademark violations, domain name disputes, spamming, computer viruses, and terrorist and pornographic websites, the lexicon and parameters of discourse eventually shifted; thereby generating sufficient support for multilateral discussions on the matter. But even arriving at a working definition of Internet governance has proven to be a highly contentious affair, with divergent ideological viewpoints influencing any proposed recommendations.

After much discussion and debate, the UN-sponsored Working Group on Internet Governance (WGIG), publicly recognized the eclectic character of the current system of multijurisdictional Internet governance, noting that a wide array of loosely-connected non-profit corporations, voluntary associations, boards, intergovernmental bodies, etc., have systematically devised "shared principles, norms, rules, decision-making procedures, and programs that shape the evolution of use of the Internet" de Bossey [1]. Put in this context, Internet governance includes not only the guidelines and regulations issued by intergovernmental agencies such as the International Telecommunications Union (ITU) and the World Intellectual Property Organization (WIPO), but also the actions, policies, and directives of reputedly non-national private-sector bodies such as the Internet Corporation of Assigned Names and Numbers (ICANN), the Internet Society (ISOC), the Internet Assigned Numbers Authority (IANA), the World Wide Web Consortium (W3C), the Internet Architecture Board (IAB), and the Internet Engineering Task Force (IETF).

In spite of the definition adopted by WGIG, and later ratified at the first World Summit on the Information Society (WSIS) held in Geneva during December 2003, the concept of Internet governance has been employed by various actors in divergent frameworks, contextualised to fit particular political orientations and objectives. Like the concept of governance in general, Internet governance continues "to mean different things to different people" (Hyden et al. [2]). Indeed, the concept is subject to an expansive definition by actors who use it as justification for enhanced international regulation of the Net, while narrowly construed by others committed to maintaining the digital status quo. Those who favour the later position stipulate that non-administrative public policymaking should be the only possible concern of intergovernmental Internet 
governance, while arguing that the technical management and day-to-day operations of the Internet should be left exclusively to the private sector. Presumably, this more restrictive definition is designed to forestall any significant intergovernmental intrusion into the present U.S.-centric governance infrastructure.

Generally speaking, the debate over Internet governance focuses on what type of regulatory body (if any) is needed for maintaining an effective, smoothly functioning, Internet. Such discussions often hinge on exactly what is meant by such seemingly vague terms as regulation and self-regulation, which presumably are the main functions of the intergovernmental and privatised models of Internet governance respectively. Regulation, the more common term, can be defined as "a balancing mechanism between the goals of economic profits and collective good" Heikkla and Laine [3]. In normal usage, regulations are rules, laws, formal and informal orders, that are devised and enforced by governments. Such regulations ideally occupy a middle ground between the welfare of consumers on the one hand and the financial interests of market actors on the other. It is important to note that regulation, strictly defined, is linked inextricably with the exercise of government power.

Conversely, self-regulation implies private-sector codes of conduct and technical standards without any significant government intrusion or oversight. In its pure form, self-regulation mandates that all rulemaking, protocols, adjudication, and enforcement be internally generated; i.e., emerging from within the industry. But in reality, self-regulatory models vary substantially, depending on the extent of government involvement or sponsorship. As Price and Verhulst [4] have noted, self-regulation is "almost always a misnomer" since governments usually continue to monitor, encourage, or even subcontract with self-regulatory agencies (SRAs).

The meaning and style of self-regulation in a given state is thereby dependent on numerous factors, including the historic relationship between the public and private sectors. While some SRAs are mostly if not totally independent, others are more accurately described as private-public "hybrids" Dinwoodie [5]. SRAs vary significantly in their relative formality or informality, with some groups advancing "voluntary" regulations, while others issue binding rules and codes. In recent decades, several different SRAs affiliated with the Internet industry have emerged (e.g., ICANN, IANA, IETF), with varying degrees of US government backing and constituent support.

\section{Disaggregating the Internet ethos}

The contemporary debate over Internet governance is in many respects connected to an overarching cyberspace philosophy, or what analysts have dubbed "the ethos of the Internet" Rheingold [6], Uimonen [7]. The origins of this ethos date back to an idealistic countercultural perspective embraced by many pioneers of digital technology in the late 1960s and 1970s. This ethos, invoking a libertarian ideal, depicts cyberspace as a unique electronic frontier, one that steadfastly resists any and all attempts at governmental control or state- 
imposed regulation. But the ethos also has a distinct transnational or international side; with the Internet being described as a diffuse parallel universe that effectively links individuals who hold similar interests and concerns, regardless of their national origin or locale. Based on this cosmopolitan logic, entering cyberspace essentially transforms national citizens into global netizens, imbued with unique characteristics and prerogatives unrestrained by physical space or time.

For decades, the libertarian and cosmopolitan dimensions of the Internet ethos managed to exist side by side, without any visible contradiction. Internet pioneers in the US and Europe systematically constructed virtual transatlantic networks and nongovernmental managerial structures based on this dualistic ethos. Collaborative, yet mostly esoteric, "voluntary" organisations such as the Internet Society (ISOC) and the Internet Engineering Task Force (IETF) rendered decisions largely by "rough consensus," with little visible dissent Gould [8]. Administration of the Internet's technical infrastructure was thus the province of a relatively small number of engineers and other specialists, with limited government involvement. But as the Internet became increasingly global in scope, such decision-making methods became unwieldy and seemingly unresponsive to the interests of newer stakeholders. The introduction of the World Wide Web in the late 1980s not only opened up the Internet to commercial interests, but also vastly enhanced the Net's accessibility to nonexpert cyberspace aficionados in the US and abroad. As a result, the ethos began disaggregating, fuelled in part by new concerns surrounding the global digital divide and proposed reforms that challenged the status quo.

In true dialectical form, the two main dimensions of the Internet ethos have become progressively antithetical. While the libertarian side of the ethos embraces the values of competition and individual self-interest, its cosmopolitan counterpart stresses interdependence and communalism. This dichotomy lends itself to dissimilar approaches to Internet governance and questions of national sovereignty, with the libertarian inclination for individual freedom emphasizing regulatory minimalism through US-sponsored self-regulation, while the cosmopolitan approach prefers more expansive forms of multistakeholder international regulation.

For those who subscribe primarily to the libertarian side of the ethos, cyberspace is viewed as a collection of private resources, easily accessed by those in the know. The decentralized character of the Net facilitates the transmission of informational and technical resources to entrepreneurs and other go-getters, systematically bypassing government hierarchies and bureaucracies. From this vantage point, the present system of self-regulation of cyberspace norms and operational standards through informal nongovernmental private ordering is sufficient, vastly preferable to more centralized and potentially problematic public-sector approaches. This approach emphasizes what could be termed the economic leg of Internet governance, focusing almost exclusively on global economic integration as an overriding objective, to the exclusion of any kind of political/administrative international amalgamation. 
Along these lines, David Post [9] endorses what he calls cyberspace "exceptionalism," explaining that the state should avoid regulating any such realm in which jurisdiction is indeterminate. Inconsistent and unpredictable regulation of the same online activity in different jurisdictions is bound to be injurious, he argues, not only to commerce but also to the offline regulatory efforts of nations. Though some libertarian-leaning theorists have reluctantly recognised the need for Internet regulation, they argue that such rules should be devised and enforced only at the national level. Jack Goldsmith [10], for example, contends that state-imposed Internet regulations may be needed, but only when promulgated unilaterally. As he reasons: "The state in which the harms are suffered has a legitimate interest in regulating the activity that produces the harms."

In contrast, the cosmopolitan perspective envisions the Internet as more of a public resource, a global commons in which information and knowledge are shared without jurisdictional boundaries. From this vantage point, the Internet essentially has been "captured" by the neo-liberal hegemonic project of the Global North (and the U.S in particular), with inherently selfish, monopolistic forces reputedly seizing and hoarding the Net's technological infrastructure. Stressing the political/administrative leg, this perspective envisions the eventual internationalisation and democratisation of Internet governance. Such steps are needed to address problems associated with the North-South digital divide; otherwise, access to information technologies will continue to be distributed unevenly for the foreseeable future, leading to enhanced levels of economic and political inequality.

In explaining the need for a more internationalised approach, theorists and associated activists have contended that online transactions frequently have negative externalities that impact more than one jurisdiction or country, thereby necessitating a greater degree of intergovernmental regulatory intervention. The real danger is surrendering cyberspace to privatised oversight, thereby abdicating public-sector responsibility for protecting citizens from online abuses Samuelson [11], Zittrain [12].

Milton Mueller [13] has been highly critical of the US dominated privatised system, arguing in favor of a more multilateral and internationalised arrangement. The Internet's global character is being threatened by overly myopic American strategic concerns and prerogatives, he argues. The continued functionality of the Internet is actually placed in jeopardy by such a unilateral approach. Therefore, Mueller states that intergovernmental/multistakeholder cooperation and coordination are essential for avoiding or countering any potential disruption of the Net's technical infrastructure. Along these lines, Michael Froomkin [14] has observed that "semi-private rulemaking" by selfregulating bodies is subject to very little if any "democratic control," with such methods often lacking due process and adequate transparency. 


\section{The global controversy over ICANN}

Much of the global debate surrounding Internet governance has focused on the Internet Corporation for Assigned Names and Numbers (ICANN,) the leading self-regulating Internet governance body, chartered by the US Department of Commerce in 1998. Viewed by many as a subterfuge for asserting American hegemony in cyberspace, ICANN has become a lightning rod for global controversy. As manager of the Domain Name System (DNS), ICANN is responsible for regulating the main database of Internet site names that are divided into particular "domains" or generic categories of sites. The DNS, arranged hierarchically with top-level domains, second-level domains, and thirdlevel domains, is one of the most important aspects of the Internet's technical infrastructure. ICANN is in charge of directly supervising top-level domains (TLDs) such as .com, .org, and .net, which in turn are authorised to register second-level domain sites, and so on. In addition, ICANN oversees the introduction of new TLD categories (e.g., inc. museum, and .name) and allocates domain name space by country code (e.g., .us, .br., .cn, and .jp).

Beginning in 1999, ICANN implemented a domain name dispute resolution system that was designed to adjudicate intellectual property disagreements and trademark disputes over conflicting names for websites. Though national and subnational courts have at times asserted extraterritorial jurisdiction in such cases, ICANN, acting through its subsidiary organization, the Domain Name Supporting Organization (DMSO), has assumed primary responsibility for resolving such disputes. But many ICANN critics have opined that the organization tends to favour powerful business interests over smaller firms and associations in this regard. Most tellingly, the root zone file - a master list of all registered numbered websites on the Internet Protocol System (IPS) - is managed by ICANN but ultimately controlled by the US government.

In recent years, Southern nations such as China, India, and Brazil have raised objections over what they consider to be their relatively meagre allocation of domain name space in comparison with many Northern states. Chinese government officials, for example, have complained about their country being allocated only nine million global Internet addresses by ICANN, compared to almost twice as many for Stanford University McCullagh [15]. Bemoaning their inability to impact such technical administrative decisions, the Chinese and other developing nations' representatives increasingly have linked the current governance system to the North-South digital divide. As a Brazilian delegate at a recent intergovernmental conference noted, the digital divide is not simply about financial inequalities and access to computers and phone lines. The divide is also tied to "political inequalities, arising from the inability of developing countries to influence Internet decision-making" (Capdevila [16]).

It is important to note that the debate over Internet governance is not simply a North vs. South issue. Indeed, substantial differences have emerged between American and European legal doctrines and approaches. One of the most difficult issues in this regard is the growing problem of online invasions of privacy by corporate interests. This issue, more than almost any other, has 
effectively separated the US regulatory approach from that of the European Union Cate [17]. Rather than developing comprehensive legislation protecting online privacy, the US government has generally embraced a market approach emphasizing informal self-regulation (e.g., industry codes of conduct, contracts, privacy intermediaries) and only limited legal protections for online consumers. In contrast, the EU has embraced a comprehensive rights-based approach that emphasises the harmonisation of privacy rules among member states. Significantly, the EU has gradually moved away from unqualified support for ICANN and the US-centric model of Internet governance.

Reacting to these and other concerns, the United Nations and related intergovernmental organisations have become increasingly involved in the debate over ICANN's future and other issues surrounding Internet governance. Most noteworthy in this regard have been conferences such as the first World Summit on the Information Society (WSIS), held in Geneva during December 2003. Referring to the Internet as a "global facility," the WSIS Declaration of Principles proclaimed, "that international management of the Internet should be multilateral, transparent and democratic, with the full involvement of governments, the private sector, civil society, and international organisations." The document repeatedly emphasised the need for "improving the global coordination of the Internet's underlying resources" [18].

Most tellingly, the WSIS Declaration referred negatively to semi-private "self-regulatory arrangements," noting "it is not acceptable for these and related global governance frameworks to be designed by and for small groups of powerful governments and companies and then exported to the world as faits accompli." The document called for "public interest monitoring" of ICANN and other such bodies, while noting the need for a "predictable policy, legal and regulatory framework" at the national and international levels. WSIS formally requested that the Secretary General of the UN establish a Working Group on Internet Governance (WGIG), which would be responsible for proposing a plan of action.

\section{Resistance and reform}

Confronted by accusations of lacking transparency and favouring American political and corporate interests, ICANN's leadership has in recent years initiated reforms designed to bolster the organisation's flagging international authority. One important step in this regard, announced in October 2002, included an expanded role for representatives of sovereign states in ICANN's bureaucracy through the creation of a Government Advisory Committee (GAC). The GAC was granted voting representation on the nominating committee for new ICANN Board members, a permanent nonvoting liaison position on the Board, and the power to make non-binding recommendations on any issue brought to the Board.

ICANN took additional steps intended to internationalise the body in June 2003 , including the prospective formation of new local and regional "at-large" groups around the world. An At-Large Advisory Committee was created for the purpose of coordinating these groups, with the stipulation that Regional At-Large 
Organisations (RALO) be formed only when there are a sufficient number of local groups in each geographic region. A more recent step taken in March 2004 was the establishment of the Country Code Names Supporting Organisation (ccNSO), a new subsidiary group that reputedly represents the interests of participating nation-based domains.

But despite these reforms, the level of international criticism concerning ICANN has only intensified. Such dissent became particularly pronounced soon after the US government declared categorically in June 2005 that it would "maintain its historic role in authorising changes or modifications to the authoritative root zone file." This statement emphasized that ICANN, operating under US governmental "oversight," would continue managing the Internet's domain name and addressing system for the foreseeable future. Expressing a strong commitment to "market-based approaches and private sector leadership," the memorandum reiterated the Bush Administration's opposition to any major changes in the current Internet governance paradigm.

The US statement was aimed apparently at influencing the subsequent WGIG meeting of July 2005 in Brussels. In discussions at WGIG, representatives of developing countries such as China, Brazil, and India repeatedly expressed concern over America's alleged unilateral approach to cyberspace governance. An Indian delegate maintained that ICANN and other non-national governing bodies are inherently undemocratic and elitist. In their stead, it is "necessary to have a mechanism which truly represents the global Internet users," he proclaimed. A Salvadoran representative echoed such sentiments, noting that "real multilateralism" in cyberspace governance was needed. A Brazilian delegate, arguing in essence that ICANN was undemocratic and a mere appendage of the US government, cited as evidence the body's highly controversial approval of .xxx, a new top-level generic domain for pornographic websites, that was later withdrawn under pressure from the Bush Administration. ICANN's initial decision to approve this new domain was made with very "little public discussion," the delegate noted [19].

Delegates associated with ICANN, the Internet Engineering Task Force, the International Chamber of Commerce and representatives of other sympathetic groups also attended the Brussels meeting, though the US declined to send any official delegation. Several delegates dismissed assertions that ICANN and other US-based self-regulatory agencies were mere lapdogs for the US government. Rebuffing such criticism, a prominent ICANN representative from the US contended that the organization had become progressively internationalised and "did not speak on behalf of the US government." Another delegate railed against the prospect of establishing any new Internet governance body, noting that "the creation of a new body would be duplicative, counterproductive, and unnecessarily costly" [19].

Significantly, WGIG's July 2005 report recommended the establishment of a new U.N.-affiliated "global multi-stakeholder forum" in which Internet-related public policy issues would be addressed. Four alternative models for Internet governance reform were proposed, scheduled for further consideration. Only one of the four models came even close to endorsing ICANN, albeit with 
important qualifications and recommendations for enhanced international input regarding policy decisions. The other three proposals called for dramatic changes in the status quo, with the establishment of various new global governance bodies designed either to replace or directly manage ICANN. In an apparent rebuff to the U.S. the report noted, "No single government should have a preeminent role in relation to international Internet governance" [1].

\section{An expanding mosaic}

The most recent round of WSIS, held in Tunis during November 2005, involved a more direct US government presence, with top-level officials such as Commerce Department Assistant Secretary Michael Gallagher and Ambassador David Gross (Coordinator for the State Department's International Communications and Information Policy) in attendance. These officials orchestrated a concerted disinformation campaign, in an obvious attempt to head off any major new initiatives that might potentially lead to ICANN's demise or radical restructuring. In this regard, Gallagher, Gross, and other officials gave numerous interviews to the press warning of a possible UN "takeover" of the Internet. They repeatedly invoked the specter of "some sort of amorphous intergovernmental group made up of countries such as Iran, Cuba, and the like" seizing control of the Net [20].

Such scare tactics apparently paid off, as the Summit seemingly backed away from proposing any dramatic changes to the digital status quo. However, at least one important progressive step was taken by the conference: the formal establishment of a new intergovernmental, UN-chartered, Internet Governance Forum (IGF). This new body will contain official representatives from virtually all nation-states, as well as from civil society and the private sector. Billed as a "multi-stakeholder" agency, the group's apparent mandate is to advise on "public policy" issues of Internet governance, rather than purely technical or operational matters.

Coupled with the promise in the final WSIS document for "the development of globally applicable principles on public policy issues associated with the coordination and management of critical Internet resources," the IGF may evolve into a major multijurisdictional power broker. Indeed, one new piece in the Internet governance mosaic was created by this assemblage, which together with ICANN's Government Advisory Committee (GAC) and Country Code Names Supporting Organisation (ccNSO) may eventually disrupt the digital status quo.

\section{Conclusion}

The current dispute over global Internet governance is linked inextricably to the North-South digital divide and the relatively recent fragmentation of the Internet ethos. At centre stage in this debate has been a Southern rebellion of sorts, erupting in reaction to the perceived dominance of the US-centric hybridized model of Internet governance. ICANN, in particular, has become a major source of global discord, due in large measure to the body's direct ties to the US 
Department of Commerce and widespread perceptions of corporate favouritism. As has been apparent at recent UN-sponsored gatherings, many in the world view ICANN as an artifice for asserting American extraterritorial jurisdiction in cyberspace. The Bush Administration's proclamation declaring the US government's indefinite unilateral control of the root zone file, coupled with its recent involvement in the .xxx debacle, has further fuelled such concerns.

With the fracturing of the Internet ethos, rifts have emerged between those who view the Net as a private resource and those envisioning it as more of a public utility. While libertarian-minded theorists have become increasingly supportive of the Global North's neo-liberal agenda (that is to say, expanding "free trade" and economic integration), those with more of a cosmopolitan bent have begun championing the beleaguered, technologically deprived, peoples of the Global South. This debate has spilled over into the intergovernmental arena, as discussions over the global digital divide have begun to focus more on the political/administrative governance of the Net, rather than simply economic/ technological disparities.

To its credit, ICANN has taken tentative steps to internationalise parts of its bureaucracy, through the establishment of new subsidiary bodies that include a broader range of international (and Southern) participants (e.g., GAC, ccNSO). But these organisations largely operate in an advisory capacity, having not yet assumed any significant administrative or political authority. As a result, national governments and other stakeholders in the Global South continue to have very little - if any - direct involvement in the regulation of the Internet's technical infrastructure. Decisions concerning the relative allocation of domain name space by country code, for instance, still appear to favour Northern - and especially American - political, economic, and academic elites.

If a global solution cannot be reached on this issue, there is the possibility albeit a worst-case scenario - that one or more rebellious Southern nations might decide to form their own alternative root for the Internet, detached from the core and not regulated by ICANN. Highly populous Southern nations such as China, India, and Brazil are potential candidates in this regard. Representatives of these countries - along with Cuba, Syria, and other so-called "radical" states - have been among the most outspoken critics of the U.S.-centric paradigm at recent global forums. Such states might decide at some point to start assigning website addresses and corresponding domain names unilaterally, beyond their own country-code quota. This could seriously compromise the Net's overall interoperability (that is to say, common operating standards and protocols), particularly if multiple websites are registered under identical or very similar domain names or addresses (Geist [21]).

In spite of ICANN's recent attempts to reform and internationalise its bureaucracy, there is little hope that it can truly redeem itself at the global level. Put simply, many important actors involved in global Internet commerce and governance do not trust ICANN (let alone the US government) to act impartially and without prejudice. Trust, as a form of social capital, is a "key concern" in the Information Age due to the "impersonal nature of online environments, the extensive use of online communications, the uncertainty of open infrastructures 
for transactions, and the relative newness of the medium" (Nandhakumar et al. [22]).

There are certainly not any easy solutions to this digital dilemma. But one thing is clear: Maintaining the US-centric status quo is a highly risky proposition that could eventually have an adverse impact on Net's interoperability. Thus, America's long-term national security and economic concerns are dependent upon resolving this issue in a fair and equitable way. At the very least, ICANN's existing multinational subsidiary organisations (e.g., GAC, ccNSO) should be vastly strengthened to provide for greater international/intergovernmental input into the body's decision-making processes. Preferably, ICANN should be fully restructured and democratized, thereby ending the US government's unilateral regulatory monopoly.

Though far from a perfect venue, the United Nations seems best poised to oversee a transfer of administrative/political power from the current selfregulatory system into a new or revamped intergovernmental multi-stakeholder treaty-based body. Care should be taken, however, not to over-regulate the Net, which has expanded and flourished in part because of its heterogeneity and relative flexibility. But more direct international involvement in Internet governance is necessary for reestablishing global trust and redistributing regulatory power more equitably. The newly established Internet Governance Forum potentially can lay the necessary groundwork for such a progressive transformation.

\section{References}

[1] De Bossey, C., Report of the working group on Internet governance, 2005. Online. http://www.state.gov/e/eb/rls/rpts/othr/49653.htm

[2] Hyden G., Court J. \& Mease, K., Making Sense of Governance: Empirical Evidence from Sixteen Developing Countries, Lynne Rienner: Boulder, p. 12-16, 2004.

[3] Heikkla, J. \& Laine, J., Socially desirable development of m-commerce: the role of regulation, Doukidis, G., Mylonopoulos, N., \& Pouloudi, N. (eds), Social and Economic Transformation in the Digital Era. Idea Group Publishing: London, pp. 144-161, 2004.

[4] Price, M. and Verhulst, S., In search of the self: charting the course of self-regulation on the Internet in a global environment, Marsden, C. (ed) Regulating the Global Information Society, Routledge Press: London and New York, pp. 57-78, 2000.

[5] Dinwoodie, G., Designing non-national systems: the case of the Uniform Domain Name Dispute Resolution Policy, William and Mary Law Review, 2001.

[6] Rheingold, H., Smart Mobs: The Next Social Revolution, Perseus: Cambridge MA., pp. 47-49, 2002.

[7] Uimonen, P., Networks of global interaction, Cambridge Review of International Affairs, 16(2), pp. 273-277, 2003. 
[8] Gould, M., Locating Internet governance: lessons from the standards process, Marsden, C. (ed), Regulating the Global Information Society, Routledge Press: London and New York, pp. 193-210, 2000.

[9] Post, D., Against against cyberanarchy, Thierer, A. \& Crews, C. (eds) Who Rules the Net? Internet Governance and Jurisdiction, Cato Institute: Washington, D.C., pp. 71-89, 2003.

[10] Goldsmith, J., Against cyberanarchy, Thierer A. \& Crews, C. (eds), Who Rules the Net? Internet Governance and Jurisdiction, Cato Institute: Washington, D.C., pp. 31-70, 2003.

[11] Samuelson, P., Five challenges for regulating the global information society, Marsden, C. (ed) Regulating the Global Information Society, Routledge Press: London and New York, pp. 316-330, 2000.

[12] Zittrain, J., Be careful what you ask for: reconciling a global Internet and local law, Thierer, A. \& Crews, C. (eds) Who Rules the Net? Internet Governance and Jurisdiction, Cato Institute: Washington, D.C., pp. 13-30. 2003.

[13] Academics call for internationalising Internet governance, Tech Web. Online at http://www.techweb.com/wire/ebiz/166403839

[14] Froomkin, M., Semi-private international rulemaking: lessons learned from the WIPS domain name process, Marsden, C. (ed) Regulating the Global Information Society, Routledge Press: London and New York, pp. 212-13, 2000.

[15] McCullagh, D., United Nations ponders Net's future, CNET News, Online http://news.com.com/2100-1028-5179694.html

[16] Capdevila, Gustavo, Internet: Groups meet to hash out who's in charge, Inter Press Service English News Wire, 2005.

[17] Cate, Fred H., Privacy protection and the quest for information control, Thierer, A. \& Crews, C. (eds), Who Rules the Net? Internet Governance and Jurisdiction, Cato Institute: Washington, D.C., pp. 297-332, 2003.

[18] Declaration of principles World Summit on the Information Society Website. http://www.itu.int/wsis/docs/geneva/official/dop.html

[19] Open consultations of the fourth meeting of the Working Group on Internet governance. Online http:/www.wgig.org/Junescriptmorning.html

[20] Governing the Internet, U.S. Department of State Website. Online http://www.state.gov/e/eb/rls/rm/2005/54794.htm

[21] Geist, M. The battle for control of the Internet The Toronto Star, 11 July 2005. Online. http://www.mgblog.com/resc/july112005.html

[22] Nandhakumar, J. \& Panteli, N., Powell, P. \& Vidgen, R., Trust in the digital era, Doukidis, G., Mylonopoulos, N., \& Pouloudi, N. (eds), Social and Economic Transformation in the Digital Era, Idea Group Publishing: London, pp. 77-94, 2004. 